\title{
Projeto Paralapracá: uma experiência de formação de formadores e (trans) formação da educação infantil
}

Maria Thereza Marcilio* Mônica Martins Samia **

*Gestora institucional da Avante

- Educação e Mobilização Social E-mail: mariathereza@avante. org.br

**Consultora Associada da Avante - Educação e Mobilização Social

E-mail: monicasamia@avante. org.br
Resumo: Este relato de experiência visa compartilhar o percurso e alguns resultados do projeto Paralapracá, desenvolvido desde 2010 em dez municípios da região Nordeste, com o objetivo de contribuir para a melhoria da qualidade do atendimento às crianças que frequentam a educação infantil, por meio de duas linhas de ação: formação continuada e acesso a materiais de qualidade. A formação é realizada a partir de eixos considerados centrais para o currículo deste segmento e se destina aos coordenadores pedagógicos, por serem os profissionais responsáveis pela formação dos professores. Suas bases são as dimensões pessoal, profissional e institucional, as práticas pedagógicas como objeto de reflexão, os saberes e a cultura locais como fundamentais no currículo, e o compromisso com o desenvolvimento da autonomia dos profissionais e com o fortalecimento de políticas públicas voltadas para este segmento.

Palavras-chave: Educação infantil. Formação continuada. Educação de qualidade. 
“Porque se a gente fala a partir de ser criança, a gente faz comunhão: de um orvalho e sua aranha, de uma tarde e suas garças, de um pássaro e sua árvore. Então eu trago das minhas raízes crianceiras a visão comungante e oblíqua das coisas."

(Do livro Memórias inventadas - As Infâncias de Manoel de Barros, São Paulo: Planeta, 2010, p. 187)

O Paralapracá é um projeto do programa Educação Infantil do Instituto C\&A ${ }^{1}$, desenvolvido em parceria técnica com a Avante - Educação e Mobilização Social $^{2}$, e tem como objetivo contribuir para a melhoria da qualidade do atendimento às crianças que frequentam instituições de educação infantil, com vistas ao seu desenvolvimento integral, por meio de duas linhas de ação complementares e articuladas: a formação continuada de educadores e o acesso a materiais de qualidade, tanto para as crianças quanto para os profissionais.

De forma direta, atua na formação de formadores, e estes, apoiados pelo projeto e em articulação com as equipes das secretarias municipais de Educação, desenvolvem as ações formativas junto aos professores e demais membros da comunidade escolar nas próprias instituições, instaurando nelas espaços regulares de formação.

Embora a educação infantil seja reconhecida como direito da criança em vários documentos (Constituição Federal - 1988; Estatuto da Criança e do Adolescente - 1990; Lei de Diretrizes e Bases da Educação Nacional - 1996), dois grandes desafios se colocam para que seja realizada de forma universal e equitativa: um é a necessidade de expansão da oferta; outro diz respeito à qualidade do atendimento.

É em relação a este segundo desafio que o projeto Paralapracá se propôs a atuar. Assim, faz-se necessário explicitar o conceito de qualidade assumido no projeto, visto que se trata de uma concepção historicamente construída, com diferentes abordagens e filiações teóricas e políticas. No relatório Educação de Qualidade para Todos: um assunto de direitos humanos, publicado pela Organização das Nações Unidas para a Educação, a Ciência e a Cultura (Unesco) em 2008, o conceito de qualidade está assim definido:

O Instituto C\&A é uma organização sem fins lucrativos de interesse público, dedicada a promover e qualificar o processo de educação de crianças e adolescentes no Brasil. Para saber mais, acesse: 〈www.institutocea.org.br〉.

2 A Avante - Educação e Mobilização Social é uma organização não governamental criada em 1991. Com sede em Salvador, BA, sua atuação estende-se por todo o Brasil, com projetos que têm como objetivo garantir os direitos sociais básicos e o fortalecimento da sociedade civil. www.avante.org.br 
Uma educação será de qualidade se oferecer os recursos e apoios necessários para que todos os estudantes alcancem os máximos níveis de desenvolvimento e aprendizagem, de acordo com suas capacidades [...] Sob essa perspectiva, a equidade se converte numa dimensão essencial para avaliar a qualidade da educação (UNESCO, 2008, p. 41).

Aceitar, pois, a qualidade como um conceito derivado de múltiplos fatores leva à renúncia à tentação de criar um padrão único para qualificá-la e medi-la. Ao contrário, o esforço a ser feito dirige-se à definição de dimensões que possam lhe dar concretude, ao reconhecimento dos fatores que a condicionam, sejam eles os valores nos quais as pessoas acreditam, as tradições da cultura, os conhecimentos científicos disponíveis, o contexto no qual as instituições educativas estão inseridas, entre outros. Nesse sentido, a partir de um estudo de cenário da educação infantil brasileira, foram eleitos três aspectos relativos à qualidade como compromissos do projeto:

- contribuir para a formação continuada de profissionais que atuam no segmento;

- contribuir para a melhoria do acesso a espaços e materiais de qualidade para as crianças e os profissionais;

- contribuir para o desenvolvimento de práticas pedagógicas em ambientes ricos de possibilidades, com diversidade de experiências e linguagens, e enfoque lúdico.

Em relação à formação dos profissionais, mesmo não considerando a formação continuada como ação compensatória, mas como própria da natureza do trabalho docente, o cenário aponta para a centralidade dessa estratégia, tendo em vista as condições relativas à formação inicial e às demandas da profissão que requer constante atualização e reflexão.

Segundo os Referenciais para Formação de Professores do Ministério da Educação (1999), a formação é

um processo contínuo e permanente de desenvolvimento, o que demanda do professor disponibilidade para a aprendizagem; da formação, que o ensine a aprender; e do sistema escolar no qual ele se insere como profissional, condições para continuar aprendendo. Ser profissional implica ser capaz de aprender sempre (p. 63).

Assim, é fundamental o desenvolvimento de ações que possam apoiar a formação dos profissionais, objetivando a melhoria das práticas educativas específicas de cada segmento da educação básica, tendo em vista suas singularidades. 


Embora se reconheça a
centralidade do processo
formativo, é instigante
analisar como a formação
dos formadores tem ainda
uma tímida repercussão
na definição de projetos e
programas que atuem
especificamente na sua
formação3. Ao mesmo

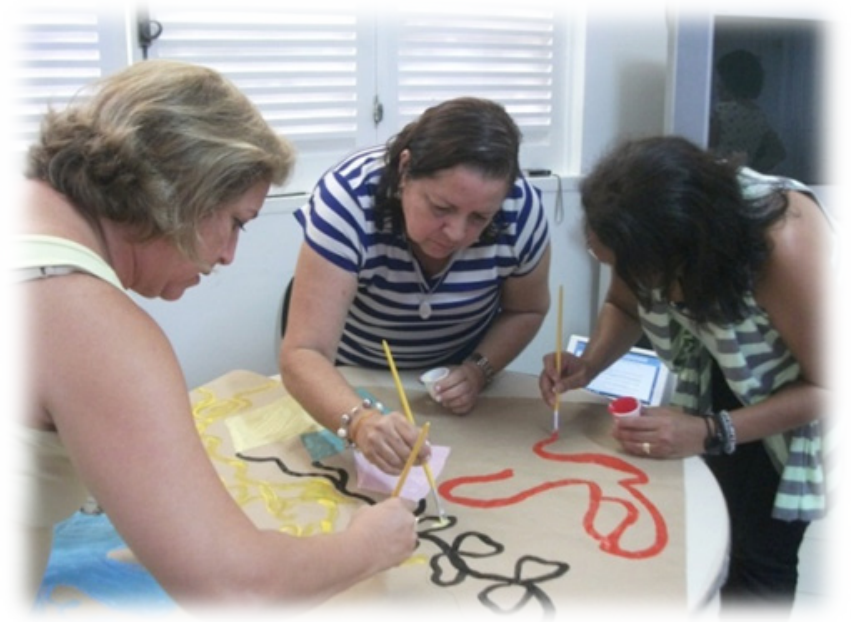

Formação de assessoras e supervisoras no eixo Artes Visuais.

tempo que os professores

têm sido reconhecidos como centro das reformas, e a formação como o instrumento mais potente para apoiá-los em relação ao seu desenvolvimento profissional e aos processos de mudança, é possível afirmar, com base na experiência e na observação do campo, que a formação de formadores apenas começa a ser debatida e, principalmente, implementada como estratégica pelas instituições responsáveis, quer seja no âmbito das universidades, dos governos ou de outras instituições formativas.

Em estudo sobre a situação da América Latina, Messina (1999) aponta um cenário semelhante:

Um ponto escassamente explorado no campo da investigação em formação docente é o saber pedagógico dos próprios formadores; esta carência é acompanhada da ausência de políticas de formação de formadores e da própria tendência destes em compreender o problema da formação como "algo" externo a si mesmos e que se refere às "condutas de entrada" dos alunos, das condições institucionais, das deficiências do currículo de formação, da falta de recursos, etc.(p.164).

3 Os estudos acadêmicos sobre os formadores ainda são escassos entre os pesquisadores brasileiros. Conforme levantamento realizado sobre o estado da arte na categoria "formação de formadores" e após refinamento relativo à natureza das pesquisas, realizado no banco de teses e dissertações da Coordenação de Aperfeiçoamento de Pessoal de Nível Superior (Capes) e do Google Acadêmico, em novembro de 2013, foram encontrados, desde 2000, apenas 12 dissertações e cinco teses relativas ao tema. Destas, apenas uma dissertação trata da educação infantil. Não foram localizados trabalhos de doutorado sobre o tema neste segmento da educação básica.

4 Tradução das autoras. No original: "Un punto escasamente explorado en el campo de la investigación en formación docente es el saber pedagógico de los propios formadores; esta carencia va de la mano de la ausencia de políticas de formación de formadores y de la propia tendencia de estos a comprender el problema de la formación como "algo" externo a sí mismos y referido a las "conductas de entrada" de los estudiantes para 


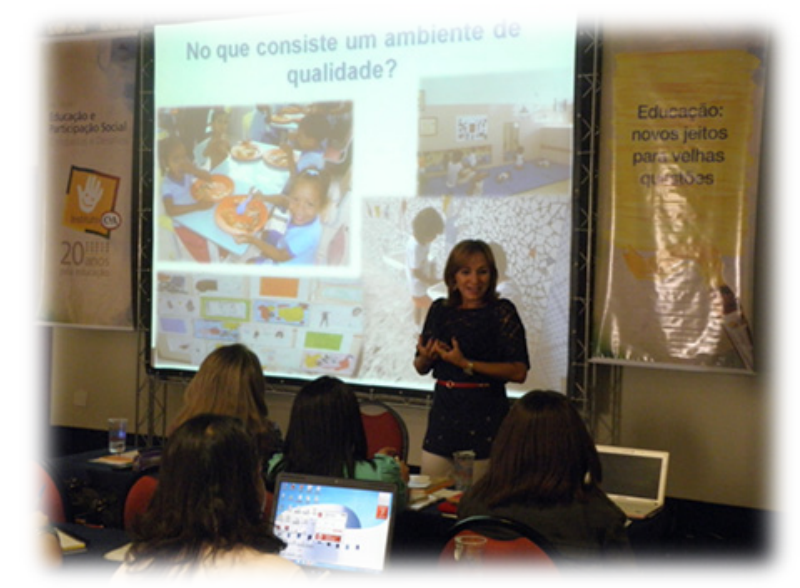

Quanto à qualidade dos ambientes, os estudos e pesquisas são ainda mais escassos e há poucos dados disponíveis, o que por si só já é um indicativo da pouca atenção dedicada ao assunto. Não obstante, alguns desses dados são bastante reveladores da realidade. Segundo o Conselho de Desenvolvimento Econômico e Social (CDES), em 2007, pouco mais da metade (53,5\%) das instituições de educação infantil brasileiras tinham parque infantil. Em 2008, foi criado um programa federal específico, o Programa Nacional de Reestruturação e Aquisição de Equipamentos para a Rede Escolar Pública de Educação Infantil (Proinfância), que destina recursos da União para a construção, melhoria da infraestrutura física, reestruturação e aquisição de equipamentos, visando à melhoria das condições físicas e materiais das instituições de educação infantil. Pela primeira vez, em 2012, a Secretaria de Educação Básica do Ministério da Educação (MEC), juntamente com o Fundo Nacional de Desenvolvimento da Educação (FNDE), realizou audiências públicas para discutir a compra de brinquedos para creches e pré-escolas e já disponibiliza um portal que facilita essas aquisições ${ }^{5}$. Recentemente, o MEC publicou um manual de orientação pedagógica específico, denominado Brinquedos e brincadeiras nas creches (2012), que também cumpre importante papel nesse contexto. Essas iniciativas revelam a necessidade de investimentos, considerando o impacto dessa variável para o atendimento de qualidade, mas ainda há um longo caminho a percorrer, tendo em vista que é necessário eliminar a precariedade encontrada nas instituições e mudar a própria concepção sobre o tipo de equipamentos e brinquedos mais adequados às faixas etárias. Ainda há uma tendência forte a uso de materiais de plástico, com fins pedagógicos específicos e de qualidade duvidosa.

No que concerne ao currículo, muitos têm sido os avanços na produção documental, com destaque para a revisão das Diretrizes Curriculares Nacionais de Educação Infantil (DCNEI) em 2009, com ampla participação

profesor, las condiciones institucionales, las deficiencias del currículo de la formación, la falta de recursos, etc.".

〈http://www.fnde.gov.br/portaldecompras/index.php/produtos/brinquedos/ brinquedos-apresentacao». 
de instituições educacionais. Entretanto, apesar deste e de tantos outros documentos norteadores, nota-se uma distância significativa entre as orientações nacionais e o que ocorre no cotidiano das instituições. Esse distanciamento se evidencia de várias maneiras, desde as diferentes ênfases dadas às linguagens no cotidiano, notadamente com maior peso para a linguagem verbal e a matemática, ao currículo centrado em atividades propostas pelos professores, com pouca escuta às crianças e ambientes organizados de forma a permitir pouca autonomia. Outro exemplo disso é a pressão por processos de escolarização e alfabetização nos moldes do ensino fundamental, o que tem levado muitas secretarias de Educação a optar por investir em livros ou materiais didáticos escolarizados. Esses materiais, além de não irem ao encontro de normas e diretrizes para a educação infantil, empobrecem a oferta e limitam as possibilidades de exploração, criação e aprendizagem das crianças, bem como vão de encontro às metodologias que privilegiam os aspectos lúdico e experiencial, característicos deste segmento.

Diante de um cenário de expansão da oferta, problemas em relação a recursos humanos, estrutura física e currículo, torna-se fundamental desenvolver ações que colaborem para o enfrentamento desses desafios. Foi neste contexto que nasceu o Paralapracá, como um projeto que pretende contribuir para o enfrentamento dessa problemática e sua gradual superação.

Assim, o Paralapracá a contribuir para o fortalecimento das redes municipais, no sentido de implementar ou desenvolver políticas públicas para a educação infantil. Para isso, compreende como condição sine qua non a formação de formadores, incluindo as equipes técnicas locais, que se responsabilizam pela formação permanente dos educadores e pela continuidade das ações implementadas pelo projeto.

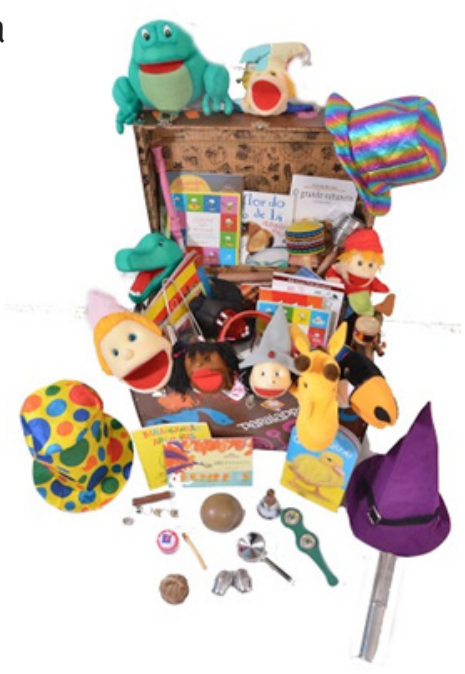

\section{ESTRUTURA E FUNCIONAMENTO DO PROJETO}

0 primeiro ciclo do projeto foi realizado entre 2010 e 2012, em parceria com cinco redes municipais de Educação no Nordeste, a saber: Feira de Santana (BA), Caucaia (CE), Teresina (PI), Campina Grande (PB) e Jaboatão 
dos Guararapes (PE); selecionadas a partir de edital. Desde 2013, iniciou-se o segundo ciclo, com mais cinco municípios nordestinos: Natal (RN), Maceió $(A L)$, Camaçari (BA), Maracanaú (CE) e Olinda (PE). Nesses dois ciclos, o projeto contempla entre 25 e 30 instituições em cada município, totalizando mais de 275 instituições de educação infantil, com quase 40 mil crianças de até 5 anos, mais de 2 mil professores e mais de 400 coordenadores pedagógicos e técnicos das secretarias de Educação.

A formação é realizada de forma semipresencial, a partir de seis eixos, considerados centrais para o currículo da educação infantil, conforme documentos nacionais, a saber: Brincadeira, Arte, Música, Literatura, Organização do Ambiente e Exploração do Mundo Físico e Social.

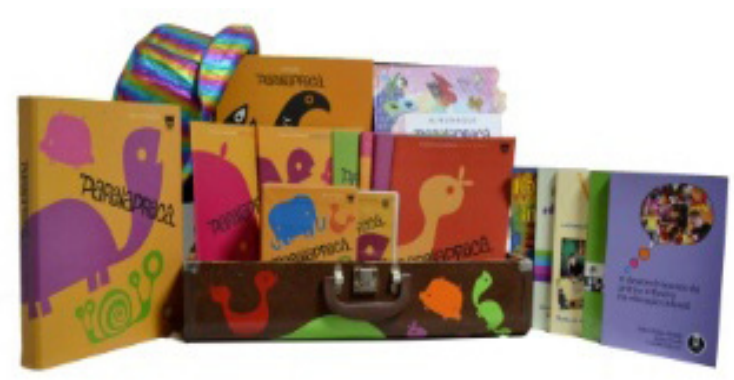

Baú Paralapracá.

As instituições recebem o Kit Paralapracá6, com vistas a contribuir para o acesso a materiais de boa qualidade, sendo esta uma inovação do projeto: aliar uma proposta formativa ao acesso a

materiais, tanto para os profissionais quanto para as crianças.

A formação nas redes se dá por meio de uma assessora, que é a formadora local do projeto e tem como parceira uma supervisora, que é uma técnica da Secretaria de Educação, responsável pela gestão do projeto no município. As assessoras e supervisoras são formadas pela Avante - Educação e Mobilização Social, instituição responsável pela implementação e monitoramento do projeto, por meio de encontros de formação itinerantes que acontecem nos municípios, trimestralmente. Nesses momentos, são realizadas oficinas relativas ao eixo abordado, sempre buscando parcerias com especialistas locais. Também são realizadas visitas a instituições para favorecer trocas e aprendizagens oriundas de cada realidade, bem como momentos dedicados ao monitoramento do projeto, em que são analisados os desafios e os avanços e elaborados encaminhamentos de forma coletiva.

Além dos encontros itinerantes, há um processo permanente de comunicação usando as tecnologias, como site, ambiente virtual de aprendizagem, e-mail, etc., bem como visitas periódicas da coordenação do projeto aos municípios para acompanhar e apoiar as equipes locais.

6 Todos os materiais criados para orientação dos profissionais estão acessíveis em PDF no site do projeto: 〈www.paralapraca.org.br〉. 
Em cada município, as assessoras realizam ações de formação junto aos coordenadores pedagógicos (ou demais profissionais que atuam como formadores), bem como com a equipe de educação infantil da Secretaria de Educação. Sempre que se inicia a formação em um novo eixo, realizam um encontro de mobilização com os gestores para que estes possam apoiar as ações em cada escola. As assessoras também fazem visitas periódicas às instituições parceiras, a fim de apoiar a prática dos coordenadores na sua função de formadores e monitorar o desenvolvimento do projeto, coletando dados para ser abordados nas formações. As visitas têm um caráter duplo, atendendo tanto às demandas do monitoramento quanto às de formação.

Avalio que as visitas são fundamentais para o acompanhamento do Paralapracá. São ocasiões em que podemos presenciar o relacionamento entre as pessoas, o envolvimento, participação ou rejeição no cotidiano das ações do projeto, os encaminhamentos dados em relação às questões surgidas, as dificuldades de concepção sobre Educação Infantil, o papel das crianças como protagonistas das suas rotinas, a relação com a comunidade. Não dá para não ter visitas, é condição para análise da prática (assessora Geisa Andrade, Relatório de Monitoramento de Maceió, 2013).

Os coordenadores pedagógicos ou outros profissionais indicados pelas redes são os responsáveis pela formação dos professores. Esta se dá no lócus das instituições de educação infantil e acontece regularmente, não em uma perspectiva de "repasse" ou multiplicação, mas de apropriação, autoria, com base na homologia de processos. Essa concepção, defendida no material orientador do projeto,

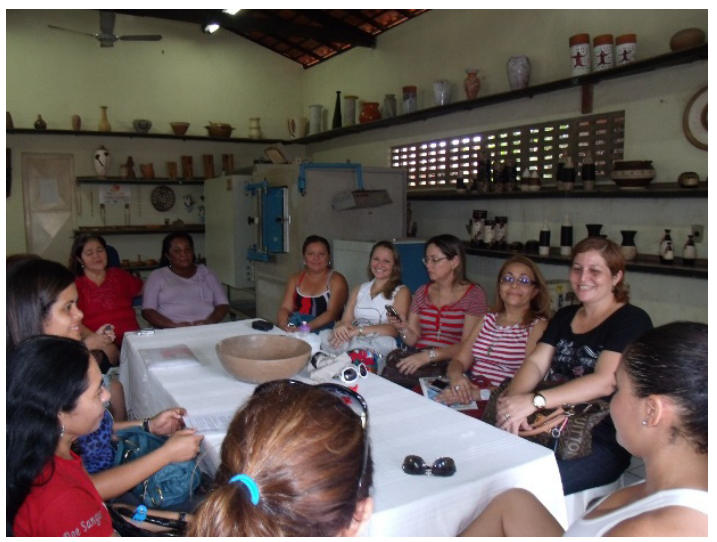

rompe com a ideia de 'repasse', de 'alguém que sabe ensinando a outros que não sabem', de algo pronto que precisa ser multiplicado. Ao contrário, defende a autoria de cada sujeito da formação que, a partir das experiências vividas, elabora e produz novas experiências (Caderno de Orientação: o coordenador pedagógico e a formação continuada, 2013, p. 34). 
A opção pela formação de coordenadores justifica-se pela intenção do projeto de fortalecer e apoiar seu papel de formador junto aos professores da educação infantil. Espera-se que, ao se tornarem mais competentes e autônomos, possam também formar professores que adquiram este perfil, utilizando os materiais do projeto Paralapracá como apoio, com progressiva autonomia e competência.

Esta opção pela atuação junto aos coordenadores pedagógicos é intencional, porque, embora tenham uma função estratégica, em geral, sua figura ou é inexistente ou estáainda distante da prática do professor e do acompanhamento ao processo de desenvolvimento das crianças. Muitas vezes esses profissionais estão muito mais envolvidos com as atividades burocráticas e administrativas, assumindo um papel mais parecido com o de um "gerente pedagógico", que se responsabiliza apenas pela fiscalização e gestão do cotidiano. Na verdade, em muitos casos, falta ao coordenador pedagógico competência técnicopedagógica para promover o desenvolvimento profissional dos educadores que estão sob a sua responsabilidade.

Pesquisa realizada no Brasil em 2010 e 2011 mostrou resultados importantes acerca do perfil do coordenador pedagógico. Vejamos a análise de alguns resultados ${ }^{7}$ :

A pesquisa da Fundação Victor Civita sobre o tema detectou que 9\% reconhecem não cumprir sua missão primordial. Já a maioria que diz exercer esse papel nem sempre o faz bem feito; $26 \%$ admitem ser insuficiente o tempo dedicado ao projeto político-pedagógico (PPP),

cuja criação coletiva é atividade-chave no processo de formação docente. Dos $87 \%$ que apontam a gestão da aprendizagem como uma atividade sob sua responsabilidade, só 17\% citam a observação do trabalho do professor em sala de aula - comprovadamente uma das principais estratégias formativas - como parte da sua rotina. Por outro lado, metade declara atender diariamente a telefonemas de todos os tipos, o que ocupa boa parte do expediente. E a atuação sem foco nem é uma questão de falta de experiência: em média, eles ocupam o posto há cerca de sete anos (SERPA; PAULINA, 2011, p. 14).

Nos dez municípios atendidos pelo projeto, em nenhum deles havia, até então, uma ação específica e regular de formação para esses profissionais. Por considerar essa uma realidade a ser problematizada e transformada, a metodologia do projeto Paralapracá visa apoiar os coordenadores pedagógicos para que estes possam assumir, progressivamente, o desafio de atuar como interlocutores qualificados no processo de formação dos educadores da educação infantil.

O coordenador pedagógico e a formação de professores: intenções, tensões e contradições. Fundação Victor Civita, 2011. Acesse: 〈www.fvc.org.br/pdf〉. Leia diferentes indicadores de desvios de função do coordenador pedagógico na revista Nova Escola, n. 6, jun. 2011. Edição especial. 
O paradigma da formação adotado é um destaque do projeto, pois valoriza a prática pedagógica como objeto privilegiado de análise e reflexão. Essa perspectiva considera os educadores como sujeitos ativos, acolhe suas representações e pontos de vista, problematiza situações didáticas, promove reflexões sobre diferentes modos de organização do trabalho pedagógico e fomenta o registro das práticas na educação infantil, como relata Fabíola Bastos, assessora do primeiro ciclo em Feira de Santana (BA):

Para romper com a histórica dicotomia entre teoria e prática, a qual fez com que as formações de professores fossem balizadas por referências externas, ou seja, teóricas, mais do que as que nascem no exercício da profissão, propomos, inspirados em Nóvoa, "instituir as práticas profissionais como lugar de reflexão e de formação”. Centrar a formação na prática significa voltar a atenção para as situações reais que existem e se desenrolam no cotidiano das instituições. Ou seja, debruçar-se sobre as diversas problemáticas relacionadas ao processo educacional vivenciadas nas instituições para buscar os conhecimentos teóricos necessários à sua compreensão e/ou solução.

Considera, ainda, os saberes e a cultura locais como elementos fundamentais no currículo; abrange as dimensões pessoal, profissional e institucional e tem compromisso com a autonomia dos profissionais e a formulação ou fortalecimento das políticas públicas relativas a esse segmento. Assim, a formação se constitui em uma prática social de caráter histórico e cultural que vai além da prática docente, abrangendo aspectos da proposta pedagógica da escola, das relações desta com a comunidade e a sociedade, bem como a subjetividade do educador e sua relação com a profissão:

\footnotetext{
O Paralapracá busca valorizar e fortalecer os saberes e experiências locais, e este direcionamento tem feito diferença em tempos de globalização, de identidades submergidas. Neste sentido, tem sido uma oportunidade de qualificar e colaborar na construção de políticas, trazendo no bojo concepções de criança, de infância, de sociedade e de cultura de um tempo histórico cujo principal demarcador tem sido o respeito aos sujeitos e suas formas de ser e de viver (Cida Freire, assessora do projeto em Jaboatão dos Guararapes/PE no primeiro ciclo e de Olinda/PE no segundo ciclo).
}

Este modelo que propõe uma cadeia formativa, que vai desde a formação das assessoras, passando pelos formadores locais, até chegar aos professores, evidentemente oferece riscos e desafios. O principal deles refere-se à possibilidade de as distorções ou incompreensões no processo formativo dos coordenadores reverberarem na qualidade da formação junto aos professores. Entretanto, esse suposto risco é visto, nesta abordagem, como parte de um processo de aproximações, que é acompanhado e problematizado nos encontros de gestão e formação, mas assumido como parte de uma construção e de uma aposta desses profissionais, que precisam assumir a liderança pedagógica em suas instituições. Para isso, contam com o apoio das 
assessoras, da equipe da Secretaria de Educação e de seus colegas, a partir de uma rede de apoio fortalecida pelo caráter colaborativo desenvolvido nas formações.

O PROJETO EM AÇÃO

Como análise inicial da estrutura concebida ou da tecnologia do projeto, é importante destacar o efeito sinérgico das suas ações estratégicas. São muitos os depoimentos e relatos sobre a importância de associar a formação continuada ao acesso a materiais de qualidade.

Nosso desafio com o eixo que se inicia é garantir que as crianças da Educação Infantil do município de Jaboatão dos Guararapes tenham direito ao acesso da cultura das tradições das narrativas orais, bem como o direito ao acesso da linguagem formal e valorizada pela sociedade, através da escuta da leitura de histórias de escritores que escrevem bem.

Para isso temos um importante aliado na Mala do Paralapracá, que é o Almanaque, um material que oportuniza que as professoras tenham acesso a diferentes gêneros textuais, subsidiando seus planejamentos e suas ações. Como disse a doutoranda que vem se debruçando sobre o Paralapracá: "Muitas vezes as professoras saem animadas das formações, querendo colocar em prática tudo aquilo que tiveram oportunidade de refletir, mas cadê o material para isso? O projeto traz essa possibilidade, aquilo que ela viu, refletiu, pode ser concretizado com o material que ela tem disponivel" (Registro Mensal da Formação, abril de 2012, assessora Cida Freire).

Outra estrutura considerada estratégica é a gestão compartilhada, realizada pela assessora junto à supervisora e a outros membros da equipe técnica da Secretaria de Educação. Tendo essa parceria como pressuposto, o projeto oportunizou não só a tomada de decisões coletivas, respeitando a trajetória e as especificidades de cada rede, como também permitiu a disseminação e a capilaridade deste, não só nas instituições parceiras, mas também em outros âmbitos da rede.

Os encontros de gestão aconteceram de modo bastante efetivo. $O$ agendamento, $a$ sistematização, a revisão dos pontos das pautas e a busca por soluções dos desafios do Paralapracá são todos tópicos importantes, tratados durante esses encontros. $O$ vínculo assessora/supervisora foi construído ao longo desses dezessete meses do projeto, fator importante na condução e na resolução dos seus impasses (depoimento da assessora Lilian Galvão, em Relatório de Monitoramento 2011 - Campina Grande/PB).

Com base nos dados de monitoramento do projeto, é possível afirmar que, na prática, os coordenadores pedagógicos ou outros profissionais que assumem o papel de formadores têm assumido progressivamente sua função de formadores em serviço. Há, evidentemente, uma diversidade grande do ponto de vista das possibilidades e das dificuldades para tomar posse desse papel. 
Entretanto, as dúvidas da relevância de fazê-lo estão praticamente dirimidas por parte de todos. Para os coordenadores que necessitam de um apoio maior, são realizadas ações específicas nas visitas, como planejar juntos a formação, ou mesmo a assessora apoiar o coordenador neste momento, assumindo o papel de parceira. É o que conta Janaína Viana, assessora do projeto no ciclo I, em Teresina (PI):

Como enfatizei anteriormente, nos CMEI que tiveram mudanças no quadro de professores, optei por dedicar as visitas técnicas para fazer formação in loco com as novas pedagogas, fortalecendo estas e orientando quanto à inserção de novos professores no projeto (Relatório de Monitoramento 2011).

Como visto, assumir a perspectiva relatada não é uma tarefa fácil, considerando a tradição e a representação que ainda se tem de projetos que, muitas vezes, chegam para "ensinar o melhor caminho". Construir um caminho é algo que, por vezes, causa estranheza e até mesmo críticas. Essa atitude é compreensível e de forma alguma fragiliza a metodologia adotada. É possível afirmar que a opção pela formação de formadores é muito acertada, mesmo com as grandes dificuldades e desafios enfrentados, diante de redes que ainda não têm uma política que assegure boas condições estruturais de trabalho e uma clareza da identidade e função deste profissional, especialmente da sua função como formador. É exatamente por esse contexto, na maioria das vezes adverso, que os resultados são tão expressivos.

O estranhamento inicial de optar pela formação de formadores em uma perspectiva de construção e autoria tem sido superado em todos os contextos, à medida que os sujeitos envolvidos percebem a potencialidade formativa desse enfoque, que passou a ser adotado como estratégia de formação em vários municípios dos dois ciclos. Os relatos dos profissionais revelam como se sentem respeitados e apoiados e, principalmente, fortalecidos na sua função de formadores, e não substituídos por supostos especialistas do projeto.

O projeto dá liberdade pra gente, liberdade de forma que se adéque à nossa realidade. Não é um projeto fechado como outros que a gente pode ver. E o nosso papel de formador dentro da escola ficou bem presente, hoje estamos muito mais próximas das professoras. A gente acompanha melhor, elas trocam mais informações, já nos buscam mais. E aquele nosso trabalho burocrático de preencher fichas e relatórios não está mais no lugar mais importante do papel do coordenador pedagógico na escola (Maria Eugenia Melo de Souza, coordenadora pedagógica do CMEI Madre Tereza de Calcutá - Teresina/PI).

Nesse sentido, as formações in loco, mais usualmente chamadas de visitas técnicas, se destacam como uma estratégia formativa muito relevante, 
essencial à metodologia do projeto. Além desse caráter formativo, são essenciais para que a assessora conheça de perto a rede, levando para a formação essa bagagem, e permite o acompanhamento dos impactos do projeto junto às crianças. Essa ação tem se destacado como forte inspiração para que as equipes técnicas de fato se aproximem das escolas. 0 que parece óbvio, na verdade, se constitui ainda em desafio, pois muitas vezes essas equipes também se encontram às voltas com as burocracias do sistema e pouco voltadas para as questões pedagógicas.

As percepções referentes à realização das visitas técnicas confirmam a importância desta atividade enquanto espaço de escuta, problematização e suporte técnico às equipes das instituições, considerando tanto o desenvolvimento das ações formativas nas instituições, sob responsabilidade das coordenadoras pedagógicas, as ações formativas sob responsabilidade das assessoras, como a questão do acesso e utilização dos materiais,

o que envolve a equipe como um todo, e em destaque os professores (Relatório Geral de Monitoramento - 2010).

Da proximidade com a realidade das escolas e alicerçadas em um paradigma de formação centrado na reflexão da vida cotidiana das instituições, dos seus fazeres e saberes, o projeto Paralapracá instaura, na maioria dos municípios parceiros, um modelo novo de formação continuada, não alicerçada por temas, prática mais comum, mas por situações reais, que são tematizadas para se construir um processo de mudança. As temáticas são substituídas por problematizações contextualizadas, assim como por um forte componente experiencial, que assume a subjetividade como elemento inerente ao desenvolvimento profissional e humano, como revela o registro da formação realizado pela assessora de Maceió (AL), Geisa Andrade, na ocasião em que desejava instaurar uma reflexão sobre os caminhos das artes visuais nas instituições:

"Por que fazer tudo tão igual e trilhar sempre os mesmos caminhos? A arte pede liberdade!" (Caderno de Orientação: Assim se faz Arte). A frase tomou a todas de impacto, quando lida no encontro de formação. Acredito que todas, em maior ou menor grau, se reportaram às práticas das suas escolas e se sentiram meio responsáveis pelos caminhos da arte trilhados nos espaços de Educação Infantil. Tematizar as práticas de arte é fundamental e há espaço para isso nos próximos encontros. O percurso é vasto e longo, acredito.

A exemplo de Suassuna e outros vários que buscaram do outro lado do mundo, mas também nos próprios chãos e berços, os motivos para as suas artes, acredito que podemos buscar nas nossas vidas os motivos e raízes para o despertar da nossa competência criativa e poder fazer, com quantas retas precisar, o nosso castelo. Castelo que é de cada um, sem amarras, mas com liberdade e autoria. 
E foi assim, pensando em Suassuna, nas falas e imagens do Paralapracá e nos devaneios de Toquinho, que as coordenadoras pedagógicas aceitaram o convite de abrir o baú de memórias da infância e vasculhar as experiências e vivências de artes visuais. Ao som do eruditismo de Meditation from Thaís, de Nigel Hess, fechamos os olhos e descemos escada abaixo para catucar as lembranças. Depois, emoções à flor da pele, fomos à mesa onde o banquete estava posto: papéis de vários tipos e cores, tesouras, tecidos de algodão de vários padrões e cores, fitinhas, botões, sianinhas, colas coloridas, lantejoulas, tintas, pincéis. Cada uma serviu seu prato e com a base do papel paraná iniciamos a construção das nossas memórias de arte.

Ao som das Meninas de Sinhá, tesouras iam para lá e pra cá moldando papéis e panos, Cola Gliter dava luminosidade, desenhos surgiam, cenários eram criados. Vez em quando, um 'não sei fazer nada, tá difícil'. Hora de conversar ao pé do ouvido e dar uma injeção de ânimo para que o medo de criar vá bater em outro lugar...

E então, aos poucos, vimos surgindo as cores vibrantes do maracatu (quase se ouvia o som dos chocalhos!), o azul e vermelho do pastoril, a cor do mar e dos coqueiros, as aulas de bordado, os campos da roça na infância, as brincadeiras, as colagens das folhas, as músicas dos repentes, os mamulengos, a agulha de crochê e a máquina de costura da avó, os carneirinhos nas nuvens. Foi um momento bonito de se ver. As coordenadoras, como autoras absolutas dos seus desenhos e pinturas, escolhiam o traço, a cor, a disposição no papel, se pincel ou dedo, se pano ou papel, degustando cada material oferecido.

\section{$[\ldots]$}

Lembranças e mais lembranças... Mas também muitas reflexões sobre o papel de coordenadoras pedagógicas e o longo caminho a ser percorrido nas unidades de Maceió, para que as crianças, já tão arteiras, possam fazer arte com protagonismo.

Oxalá abrir os baús das memórias de arte das professoras possa ser um bom caminho para a sensibilização sobre o direito das nossas crianças de ter, além da comida, diversão e arte, com liberdade (Registro da Formação, Maceió/AL, jul. 2014).

No projeto Paralapracá, a formação dos coordenadores pedagógicos representa uma oportunidade para que estes sintam que a constituição da sua profissionalidade como formadores passa não pelo simples domínio dos saberes, mas pela possibilidade de envolver os professores em experiências ricas de reflexão, de contato com suas histórias de vida, de busca de razões sobre seu fazer, de conexão com suas representações sobre infância e educação infantil, bem como com o compromisso e a coragem para realizar as mudanças necessárias. Saber escolher aspectos que precisam ser mudados, engajar, planejar e executar as mudanças com o grupo é um dos focos deste processo de formação de formadores. 
Em termos de resultados gerais, é possível afirmar que o Paralapracá não é um projeto que "mata a fome", mas "abre o apetite". Essa afirmação sintetiza muito do propósito e dos resultados alcançados em relação à sua dimensão formativa. Mais do que trazer respostas, promove perguntas, indagações e problematizações. E estas, aliadas a estratégias de apoio, mobilizam diversos profissionais, entre técnicos, coordenadores, gestores, professores e funcionários, para que caminhem em direção às suas próprias necessidades profissionais e institucionais, buscando mudanças e soluções. Além disso, no primeiro ciclo e já como resultado do segundo ciclo, iniciado em setembro de 2013, instauraram-se nas escolas espaços regulares de formação, o que não acontecia anteriormente em nenhum dos municípios citados, visto que as formações, quando ocorriam, eram promovidas pelas equipes das secretarias de Educação. Essa iniciativa, provocada pelo projeto, promoveu um clima de reflexão e de colaboração, essenciais ao processo de aprendizagem dos profissionais, e continua gerando mudanças. Mudanças em relação à concepção de criança e de educação infantil, que impactaram em mudanças nas práticas pedagógicas, na relação professor-criança, na organização dos espaços, nas rotinas e na relação com a comunidade, dentro e fora da escola.

Não tem sido fácil para as redes implementar esses tempos de reflexão coletiva nas instituições, quer seja pela dificuldade dos ajustes no calendário dos professores, quer seja pela própria falta de cultura de formação nas escolas. A ideia da escola como espaço de aprendizagem para todos ainda não está enraizada nas realidades em que o projeto foi implementado. E esta tem sido uma grande contribuição, pois, à medida que o tempo passa, esse reconhecimento é conquistado. Em todas as redes municipais parceiras há um reconhecimento explícito da importância das formações in loco, da diferença que fazem nas propostas de mudanças e nos impactos junto às crianças. Embora no campo das ideias esta já seja uma reivindicação antiga, no chão da escola os tempos para a reflexão sobre a prática ainda estão no âmbito dos desafios, e essa conquista tem uma relevância estratégica para o projeto Paralapracá. É um legado que se pretende deixar nas redes, que, em geral, tiram seus professores das escolas para palestras temáticas que pouco impactam na vida das crianças, embora tenham seu valor no processo formativo.

Em relação à formação dos coordenadores e ao seu papel como formadores, considera-se que este é um dos impactos mais significativos do projeto 
Paralapracá, tendo em vista que é seu público direto. As contribuições do projeto para o fortalecimento desse profissional como líder das ações pedagógicas nas instituições têm feito a diferença nessas redes. Como relata Selma Bedaque, assessora de Natal (RN), “há coordenadoras pedagógicas encantando, cuidando do ambiente, dos espaços, da pauta, e buscando transformar e encontrar situações reais do próprio CMEI para enriquecer a formação". Esse processo é complexo e exige muito cuidado, estratégias formativas de apoio e muita sensibilidade para compreender o fluxo dos grupos e de cada um, pois, historicamente, o papel desses profissionais é difuso, tangenciando entre ações pedagógicas deterministas, funções burocráticas e de fiscalização e aquelas que defendemos no projeto Paralapracá, ligadas à construção coletiva de um projeto pedagógico que se materializa no cotidiano das instituições. Rita Margarete Santos, assessora de Camaçari (BA), narra desafios e conquistas que exemplificam bem o contexto do projeto:

Apesar de as coordenadoras estarem em ritmos bastante diversos, o grupo está avançando. Algumas já entendem e assumem o papel de formadoras. Outras estão 'desestabilizadas', procurando 'chão', não se sentem seguras e ainda precisam se apropriar mais do acervo do projeto. Embora lentamente, o Paralapracá está instaurando a formação nas instituições. As coordenadoras estão tomando consciência dos seus desafios e das demandas de estudo e de planejamento (Relatório de Monitoramento 2014.1).

Para potencializar esse processo, a formadora criou um grupo de e-mails e aquelas que desejam compartilham suas pautas recebem retroalimentação, tanto da assessora quanto das colegas:

A socialização das pautas tem sido muito validada pelo grupo, mesmo pelas coordenadoras que ainda não compartilham e somente recebem as produções das colegas e o meu retorno. Acredito que esta estratégia contribuiu muito para o avanço na elaboração destes instrumentos, o que reflete na melhoria da organização dos encontros de formação nas instituições. Ainda assim, algumas coordenadoras falam da sua insegurança para fazer a formação e outras dizem que fazem formação, mas a pauta está sempre 'na cabeça' e não registram.

Atualmente, as pautas focam no momento de leitura, discussão e, algumas, já 'tematizam' a prática, usando os Cadernos de Experiências do Paralapracá (assessora Rita Margarete Santos, Relatório de Monitoramento de Camaçari/BA - 2014.1).

Enfim, das muitas conquistas, nesse contexto tão desafiador, evidencia-se a consolidação progressiva do papel dos coordenadores como formadores e 0 reconhecimento da função desses profissionais nas instituições. Acompanhar este processo de mudança significa testemunhar a vida se transformando, ganhando mais sentido e motivação. 
Crianças interagindo com livros do Kit Paralapracá.

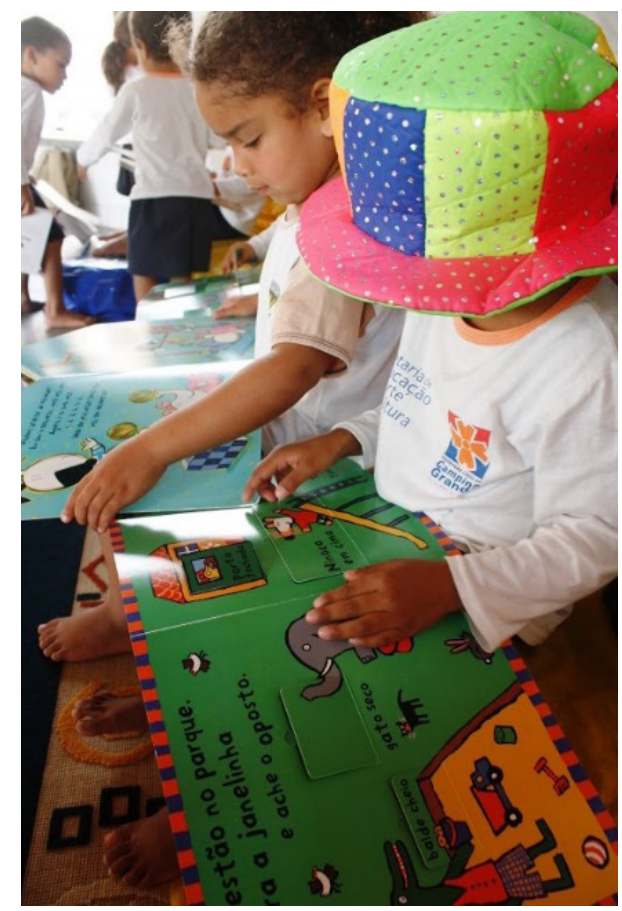

O grande norte pra mim foi a descoberta de como fazer a Educação Infantil. Eu trabalho há muito tempo com educação, mas a Educação Infantil era muito nova para mim e eu ainda não havia me encontrado. Realmente agora eu me encontrei com o Paralapracá. Foi uma descoberta e tanto e foi aí que eu vi que a gente precisava fazer uma reflexão, porque tínhamos uma ênfase muito grande na linguagem oral e escrita e os outros eixos eram sempre colocados em segundo plano. Foi uma descoberta e tanto, a cada eixo eu descubro mais, vou pesquisando, estudando. Isso que é o importante. É um despertar!

(Antônia Cordélia Pereira Fonseca de Souza, coordenadora pedagógica do CMEI Danielzinho - Teresina/PI).

Com este trabalho, o projeto Paralapracá incide em um campo ainda pouco explorado no país, como já mencionado, que é a formação de formadores, pois, ao mesmo tempo que recoloca os coordenadores neste lugar, os apoia de forma sistemática e cuidadosa, para que possam trilhar esse caminho com responsabilidade e eficiência.

Quanto aos resultados gerais junto às crianças, maior sentido de todo este trabalho, é possível verificar, nos dois ciclos, um fortalecimento da identidade da educação infantil, não como preparação para a escola, mas como espaço de vida e de experiências significativas para elas. Assim, o direito à infância está mais assegurado nas instituições parceiras, visto que foram conquistados tempos e espaços para o brincar; maior acesso às experiências que possibilitem diferentes linguagens e que incluam a cultura comunitária como elemento estruturante do currículo; valorização de modos de expressão próprios da criança pequena; e maior respeito às especificidades dos grupos (idade, 
universos socioculturais), exemplificado no registro abaixo, retirado da Pasta de Registro, que compõe o Kit Paralapracá:

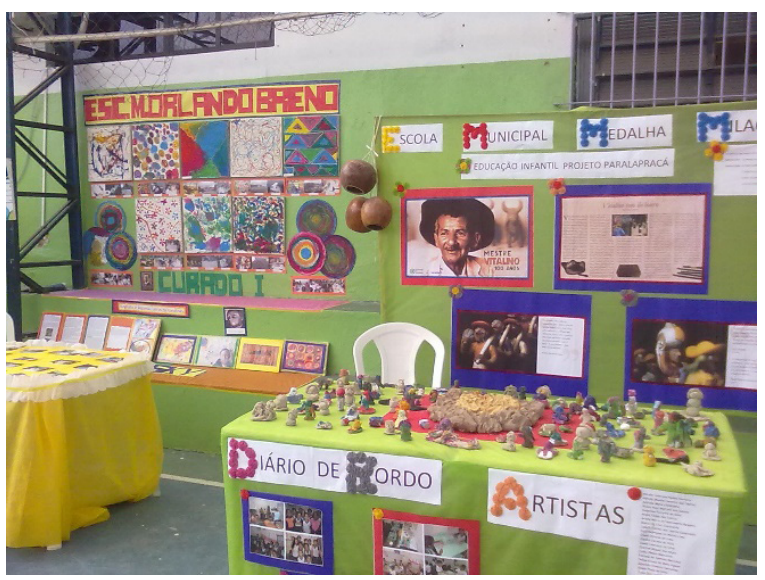

Mostra de Artes Visuais em Jaboatão dos Guararapes (PE).

Numa manhã do mês de fevereiro de 2011, ao chegarmos à escola, percebemos que não havia energia. Resolvemos fazer o planejamento de aula no pátio da escola e, de repente, presenciamos uma cena rotineira para crianças e adolescentes da comunidade, mas não nos dávamos conta. E faz aproximadamente 16 anos que trabalhamos nesta comunidade. Foi o projeto Paralapracá que nos aguçou e despertou a curiosidade de investigarmos a cultura comunitária.

Crianças e adolescentes chegaram com galeias [espécie de caixote normalmente usado para armazenar frutas e verduras] de mangas e pitombas em uma casa em frente à escola. Fomos até lá e conversamos com a dona da casa, conhecida como Dida. Ela nos relatou a importância desta colheita como ajuda para a subsistência da família. Disse também que a colheita da pitomba acontece só neste período que antecede as festividades de Nossa Senhora dos Prazeres, padroeira do bairro. A festa é conhecida como Festa da Pitomba e, por tradição, quem sobe o morro dos Guararapes desce com pelo menos um cacho do fruto, de sabor entre o doce e o azedo.

Depois decidimos acompanhar as crianças e adolescentes para vermos como acontecia o processo da colheita da pitomba. Foi interessante perceber que é um trabalho que eles fazem com prazer e alegria. Alguns sobem no pé para colher o fruto, enquanto outros aguardam embaixo com a galeia. Presenciamos também que as crianças menores, entre $2 e$ 6 anos, ficam embaixo da árvore esperando para saborear o fruto ali mesmo.

O relato da professora Andréa Mendes e da coordenadora pedagógica Maria Dulcéia, da Escola Municipal Nicea Cahú, de Jaboatão dos Guararapes (PE), prossegue, contando sobre a Festa da Pitomba e como essa expressão cultural adentrou a escola e deu sentido a uma situação vivenciada pelas crianças, mas ainda pouco valorizada pela escola. Essa experiência exemplifica a ruptura do paradoxo entre a valorização da constituição da identidade das crianças e a desvalorização da cultura comunitária na qual estão inseridas. 
No que tange ao acesso a espaços e materiais de qualidade, o projeto Paralapracá tem colaborado tanto no âmbito das instituições, mais atentas a esse aspecto, quanto no âmbito da gestão das redes, que tem valorizado essa dimensão, melhorando a qualidade das suas aquisições, bem como o provimento das instituições. Há muitos desafios em todos os âmbitos, e este é um dos que exigem mais atenção, pois as condições de oferta são ainda muito discrepantes. Mas, mesmo em situações muito precárias, houve e continua havendo melhoras. No primeiro ciclo, por exemplo, o eixo Assim se Organiza o Ambiente mobilizou toda a comunidade escolar, e houve forte envolvimento dos funcionários na confecção de materiais e (re)estruturação de ambientes como parque, horta, salas, cantos, etc. Como consequência, houve certa descentralização do papel do professor, com maior autonomia e respeito às crianças.

Participei das formações relacionadas ao eixo Assim se Organiza o Ambiente e me senti desafiada a mudar a organização da minha sala. Os vídeos e as leituras propostas pela coordenadora me fizeram refletir e me instigaram a experimentar mudanças no espaço.

Muitas ideias foram surgindo enquanto eu via o vídeo, fiz algumas anotações e não conseguia parar de pensar na minha sala. Nossa coordenadora propôs que pensássemos em mudanças possíveis em nosso ambiente para curto, médio e longo prazos. Juntamente

com as colegas, traçamos algumas possibilidades. Comecei a pensar a respeito do que era possivel fazer sozinha para organizar melhor o ambiente da minha sala. Mudei alguns móveis de lugar e a sala já pareceu ter mais espaço.

Aproveitei um dia com baixa frequência e fiz a proposta para as crianças me ajudarem a separar os brinquedos por temática. Expliquei que tudo misturado não estava legal, que não podíamos escolher uma brincadeira no meio daqueles brinquedos misturados. Assim, derramamos o balde de brinquedos e eu ia perguntando que tipo de brinquedo era e onde deveríamos colocar: Panelas?... na cozinha; a banheira?...perto das bonecas; carrinhos?...

todos juntos. Foi uma confusão! Algumas crianças pareciam não entender a lógica de estarmos separando os brinquedos e, por vezes, as mesmas crianças jogavam tudo de novo dentro do balde.

Pensei em desistir, foi desgastante explicar a mesma coisa tantas vezes! Foi um começo difícil. Arrasta daqui, arrasta dali... no final da manhã a sala parecia outra.

Não mudei a decoração, mudei as coisas de lugar. E pareceu que fiz muitas coisas... Coloquei uma estante de aço (que estava na sala encostada na parede) como divisória. Assim foram criados dois espaços: na frente a cozinha e ao fundo o teatrinho de fantoche.

Uma prateleira para telefones e teclados, duas prateleiras para carrinhos e as mais altas estão servindo para organizar o material escolar. Montei uma minicozinha com fogãozinho, geladeira, micro-ondas e uma mesa; no balde colocamos os brinquedos de cozinha (pratinhos, garfinhos, panelas, frutas e verduras). Conversei com as auxiliares da limpeza que eu tinha lido uns textos que me motivaram a reorganizar os espaços na sala e pedi que elas conservassem assim na hora da limpeza. Uma delas ao ajudar disse: 'Olha ali, tá parecendo uma cozinha'. E eu respondi: 'A ideia é essa!' [...] 
Não fiz tudo em um dia só. As mudanças aconteceram ao longo de duas semanas. Pude observar algumas crianças de outras turmas olhando pela janela com curiosidade, algumas colegas entravam, perguntavam alguma coisa, olhavam, mas não diziam nada. $O$ olhar delas me causou inquietação: o que será que estão pensando? (registro da professora Karine da Cruz Costa, da Pré-Escola Municipal Coriolano Farias de Carvalho, em Feira de Santana/BA).

Para finalizar, é preciso lembrar que certamente há muitas nuances, peculiaridades e diversidade quando se trata de resultados! Estes estão vinculados a múltiplos fatores, desde as condições políticas, administrativas e técnicas da rede, passando pela estrutura e cultura de cada instituição, até dimensões mais pessoais, como a possibilidade de reflexão e aprendizagem, a disposição para a mudança, a afinidade e a crença relativas às propostas do projeto, a continuidade ou descontinuidade das equipes, enfim, fatores ligados a um processo de formação humana que, mesmo coletivo, será sempre singular.

Ademais, o resultado mais importante é a sensação clara de que muito ainda há de se caminhar, mas que cada passo dado teve sua relevância. Certamente as redes municipais e os profissionais da educação infantil vão, progressivamente, se apropriando da possibilidade de continuar o caminho com autonomia e coragem, à medida que vivenciam essa experiência tão significativa. Em relação às redes, o compromisso com a educação de qualidade vai se fortalecendo e se expressando em ações concretas. Em relação aos profissionais, sentindo-se mais confiantes, motivados e cuidados, levam até as crianças aquilo que todo projeto de formação deveria se comprometer a oferecer: a melhoria da qualidade do atendimento às crianças que, cotidianamente, convivem e olham o mundo, muitas vezes, pela lente desses adultos. 


\section{The Paralapracá Project: an experience in training of trainers and infant education transformation}

Abstract: This account aims to share the path and some of the results of the Paralapracá Project, developed since 2012 in ten municipalities in the northeast of Brazil, with the purpose of contributing to improve infant education quality by means of two lines of action: continued education and access to quality materials. This continued education work is based on the educational sector's main curriculum cores, and is intended for teachers. Its bases are the personal, professional, and institutional dimensions, pedagogical practices as the object of reflection, local knowledge and culture as key in the curriculum, and the commitment to developing professionals' autonomy and to strengthening public policies for this segment.

Keywords: Infant Education. Continued Education. Quality Education. 


\section{REFERÊNCIAS}

BRASIL. Ministério da Educação. Secretaria de Educação Básica. Brinquedos e brincadeiras na creche. Brasília: MEC, SEB, 2012.

- Ministério da Educação. Secretaria de Educação Básica. Diretrizes

Curriculares Nacionais para a Educação Infantil. Brasília: MEC, SEB, 2010.

- Ministério da Educação. Secretaria de Educação Fundamental. Referenciais para a formação de professores. Brasília, 1999.

INSTITUTO BRASILEIRO DE GEOGRAFIA E ESTATÍSTICA (IBGE). Síntese dos indicadores sociais: uma análise das condições de vida da população brasileira. Rio de Janeiro: IBGE, 2009.

INSTITUTO C\&A e AVANTE EDUCAÇÃO E MOBILIZAÇÃO SOCIAL. Caderno de Orientação: $O$ coordenador pedagógico e a formação continuada. Barueri: SP, 2013.

MESSINA, Graciela. Investigación en o investigación acerca de la formación docente: un estado del arte en los noventa. Revista Iberoamericana de Educação, n. 19, p. 145-207, Jan./Abril 1999.

SERPA, Dagmar; PAULINA, Iracy. O coordenador pedagógico vive crise de identidade. Revista Nova Escola, São Paulo, n. 6, p. 14-18, jun. 2011. Edição Especial. Disponível em: 〈http://revistaescola.abril.com.br/pdf/coordenacaoformacao.pdf> Acesso em: 20 out. 2012.

UNESCO. Educação de qualidade para todos: um assunto de direitos humanos. 2. ed. Brasília: Unesco, Orealc, 2008.

RECEBIDO: Setembro de 2014.

APROVADO: Outubro de 2014. 